\title{
Isotretinoin Induced Hyperlipidemia and Impact of Leptin Gene rs 7799039 Polymorphism in Safety of Acne Patients
}

\begin{abstract}
Amal A Mohamed,'
Alshymaa Hassnine, (iD ${ }^{2}$

Amr Elsayed, ${ }^{2}$

Mahmoud Montaser, ${ }^{3}$

Yasmeen Ismail, ${ }^{4}$ Ahmed El-

Demery, ${ }^{5}$ Eman Sultan, ${ }^{6}$

Rania S Abdel Aziz, ${ }^{7}$

Eman Eldemiry, ${ }^{8}$ Radwa Hagag,

Amal A El-Kholy, (D) ${ }^{10}$ Eman Salah ${ }^{1 /}$

'Biochemistry and Molecular Biology Department, National Hepatology \& Tropical Medicine Research Institute, Cairo, Egypt; ${ }^{2}$ Gastroenterology and Tropical Medicine Department, Faculty of Medicine, Minia University, Minia, Egypt; ${ }^{3}$ Department of Dermatology, Andrology and STDs, Faculty of Medicine, Minia University, Minia, Egypt; ${ }^{4}$ Clinical Pharmacology Department, Faculty of Medicine, Benha University, Benha, Egypt; ${ }^{5}$ Biochemistry Department, Faculty of Medicine, October 6 University, 6th of October City, Egypt; ${ }^{6}$ Clinical Nutrition Department, National Nutrition Institute, Cairo, Egypt; ${ }^{7}$ Clinical and Chemical Pathology Department, National Cancer Institute, Cairo University, Cairo, Egypt; ${ }^{8}$ Faculty of Pharmacy, Fellow of Clinical Pharmacology, Cairo University Hospitals, Giza, Egypt; ${ }^{9}$ Pharmacy Practice and Clinical Pharmacy Department, Faculty of Pharmacy, Egyptian Russian University, Badr City, Egypt; ${ }^{10}$ Clinical Pharmacy Department, Faculty of Pharmacy, Ain Shams University, Cairo, Egypt; "'Department of Dermatology, Andrology, Sexual Medicine and STDs, Faculty of Medicine, Helwan University, Cairo, Egypt
\end{abstract}

Correspondence: Amal A El-Kholy Clinical Pharmacy Department, Faculty of Pharmacy, Ain Shams University, Cairo, Egypt

Tel +201060355448

Email Amal.elkhouly@pharma.asu.edu.eg
Background: Acne vulgaris (AV) is a chronic inflammatory disease that affects the pilosebaceous unit. Leptin (LEP) gene polymorphisms is associated with higher risk of multiple disorders. Insulin-like growth factor-1 (IGF-1) exerts comedogenic effect by stimulating the sebaceous glands. Isotretinoin is an effective oral therapy for AV with many side effects including hyperlipidemia and increased serum levels of liver enzymes. Purpose: To evaluate the impact of LEP gene rs 7799039 polymorphism in acne patients' clinical response lipid profile and liver enzymes following 6 months oral isotretinoin therapy in Egyptian AV patients.

Methods: One hundred eligible AV patients received $0.5 \mathrm{mg} / \mathrm{kg}$ oral isotretinoin for 6 months. Patients' demographics and clinical data were obtained. Body mass index (BMI), lipid profile, liver enzymes and IGF-1 were measured at baseline and after 6 months of therapy. Genotyping was done for LEP gene rs 7799039.

Results: Six month administration of oral isotretinoin in Egyptian AV patients is associated with significantly elevated aspartate transaminase (AST) in CC and AC genotypes $(\mathrm{P}<0.001)$. Significant alanine aminotransferase (ALT) elevation was observed in CC, AC and AA genotypes ( $\mathrm{P}<0.001,0.004,0.002$, respectively). Total cholesterol (TC), triglycerides (TG) and low density lipoprotein (LDL) were elevated significantly $\mathrm{P}<0.001$ ) in the three genotypes. IGF-1 was decreased significantly in $\mathrm{CC}$ and $\mathrm{AC}$ genotypes $(\mathrm{P}<0.001)$. CC genotype is associated with highest response $(\mathrm{P}<0.001)$.

Conclusion: LEP rs7799039 gene had an impact on the clinical response, lipid profile and liver enzymes in AV patients treated with oral isotretinoin. LEP rs7799039 CC genotype is predicted to be the treatment candidate for 6 month oral isotretinoin.

Keywords: leptin, IGF-1, lipid, isotretinoin, liver enzymes, LEP, insulin-like growth factor-1

\section{Introduction}

Acne vulgaris (AV) is a chronic inflammatory disease that affects the pilosebaceous unit of the skin in vast majority of adolescents. It is a multifactorial disease with underlying altered keratinization, increased sebum secretion, colonization of Propionibacterium acnes, and dermal inflammation. ${ }^{1}$ AV is a common skin disease that affects approximately $9.4 \%$ of the world's population with the highest prevalence in adolescents. It affects over $90 \%$ of males and $80 \%$ of females in all ethnic groups. ${ }^{2,3}$ The prevalence of acne in adolescents and adults differs among countries and ethnic groups. ${ }^{4}$ In Egypt, $60 \%$ of female students in secondary school reported $\mathrm{AV}^{5}$ and high prevalence of acne among adolescent females was observed. ${ }^{2,5}$ 
Although acne is linked to pubertal androgen surge at the beginning, it is more related to growth hormone and insulin-like growth factor-1 (IGF-1) during its course. ${ }^{6,7}$

IGF-1, a $7.5 \mathrm{kDa}$ single chain polypeptide, is a major homeostatic regulator of many physiological, anabolic, and metabolic processes. ${ }^{8}$ IGF-1 exerts its comedogenic effect by stimulating the proliferation of sebaceous glands and lipogenesis through potentiation of adrenal androgen and peripheral androgen signaling at the receptor level. ${ }^{9,10}$

A positive correlation is observed between IGF-1 level and sebum secretion which is reflected on severity of $\mathrm{AV}^{6,11}$ IGF-1 increases expression of elementbinding protein-1, which stimulates lipogenesis in sebocytes. IGF-1 transmits its lipogenic signal through activation of the phosphoinositide 3-kinase/Akt pathway. ${ }^{10,12}$

The adipose tissue is not only energy storage, but it also has endocrinological and immunological functions through the secretion of bioactive mediators called adipokines. ${ }^{13,14}$ One of these is Leptin (LEP), which is encoded by the LEP gene. It controls lipid and sugar metabolism, thus playing a vital role in energy consumption and appetite pathway. ${ }^{15}$

LEP gene polymorphisms is associated with high risk of multiple disorders like metabolic syndrome ${ }^{16}$ and dyslipidemia. ${ }^{17}$ LEP is controlling energy homeostasis and there is a link between LEP and IGF-1. ${ }^{18}$

Isotretinoin (13-cis retinoic acid) is an effective oral therapy of $\mathrm{AV}$ with long-term remission ${ }^{19}$. Isotretinoin exerts anti-acne effects by reducing sebum and comedogenesis. ${ }^{20,21}$ However, it has many drawbacks that might limit its use including teratogenicity ${ }^{15}$ and mucocutaneous changes. ${ }^{22}$ Moreover, isotretinoin causes hyperlipidemia and elevated liver enzymes. ${ }^{23}$ In an attempt to reduce these side effects, low-dose regimens $(0.5 \mathrm{mg} / \mathrm{kg} /$ day $)$ have been used. Many dermatologists support its use for treatment of lesser degrees of acne that produce scarring or psychological symptoms. Literature from international studies also suggests that low dose isotretinoin is useful for mild to moderate acne with less side-effects. ${ }^{24}$

We aimed to study the impact of LEP gene rs7799039 polymorphism on lipid profile, liver enzymes, IGF-1 alterations and the clinical response in $\mathrm{AV}$ patients. Therefore, an assessment of the safety and efficacy of 6 month isotretinoin therapy would be evaluated.

\section{Patients and Methods}

\section{Study Design}

This was a cross-sectional case control study that was conducted at Dermatology Clinic, National Hepatology and Tropical Medicine Research Institute, Cairo, Egypt. The study was approved by the Research Ethics Committee for human subject research at National Hepatology and Tropical Medicine Research Institute (NHTMRI-IRB-19-2020).

\section{Study Subjects}

One hundred patients were included in this study. Patients to be included in the study should have the following criteria:

1. The age between 18 and 35 years.

2. Newly diagnosed acne patients with mild to severe acne (graded on basis of IGA).

3. Patients accepted to participate in the study.

4. Patients given only oral isotretinoin as acne treatment

5. Patient or guardian agreed to sign the written informed consent before starting treatment.

Patients were excluded from the study for any of the following reasons:

1. Liver or renal diseases.

2. History of active neoplasm

3. Recent major surgical operations

4. Alcohol abuse

5. Pregnancy or child-bearing age females without adequate contraception

6. Non-compliant patients

\section{Data Collection}

Clinical data were collected from patients' files and patients' interviews. The collected data included patient's age, sex, body mass index (BMI), alcohol and any food supplement use, tobacco use and any other health conditions. BMI was calculated from patient's height and weight $\left(\mathrm{kg} / \mathrm{m}^{2}\right)$.

At baseline (before treatment) and after 6 months of treatment, all patients were assessed for BMI, aspartate transaminase (AST) and alanine aminotransferase (ALT), triglycerides (TG), high density lipoproteins (HDL), low 
density lipoprotein (LDL), total cholesterol (TC) and IGF-1.

Investigator's Global Assessment (IGA) ${ }^{25}$ was used for clinical evaluation of acne severity at base line and 6 month after treatment by isotretinoin. Score 0 (clear): Residual hyperpigmentation and erythema may be present. Score 1 (Almost clear): A few scattered comedones and a few small papules. Score 2 (mild): Easily recognizable; less than half the face is involved, some comedones and some papules and pustules. Score 3 (moderate): More than half the face is involved, many comedones, papules and pustules. One nodule may be present. Score 4 (severe): Entire face is involved, covered with comedones, numerous papules and pustules, and few nodules and cysts.

Study patients were categorized into 3 groups according to LEP rs 7799039 genotypes. Groups A patients were CC genotype, group $\mathrm{B}$ patients were AC genotype and group 3 patients were AA genotype.

\section{Drug Intervention}

All patients received an oral dose of $0.5 \mathrm{mg} / \mathrm{kg}$ Isotretinoin (Netlook $^{\circledR}$, Al Andalous pharma, Maadi, Cairo, Egypt) for 6 months. All patients were followed up monthly for treatment compliance, liver enzymes and any intolerable side effects (headache or epistaxis). All patients were taught about the importance of treatment adherence in achieving maximum treatment benefit. Response to treatment was checked by narrowing of facial pores and decrease in the shiny oily appearance of the skin. The efficacy was also assessed by the change (decrease) in the severity of acne at the end of six months according to the IGA.

\section{Blood Sampling}

Fifteen $\mathrm{mL}$ of venous blood were collected from each subject after overnight 12 hours fasting. Five milliliters were collected by vacutainer in plain tube and serum separation was performed immediately after the coagulation by centrifugation for the biochemical measurement of ALT, AST, TC, TG, HDL and LDL.

\section{Biochemical Analysis}

Lipid Profile, Liver Function Tests and IGF-I

Lipid profile that included: TC, TG, HDL, LDL and liver function analysis of AST and ALT, were assessed by wet chemistry Bachman machine AU480 auto analyzer.
IGF-1 measurement was done by Eliza DRG ${ }^{\circledR}$ IGF1600 ELISA (EIA-4140), DRG International, Inc., USA, according to the manufacture instructions.

\section{DNA Extraction and Genotyping}

For DNA extraction and detection of allelic discrimination of LEP gene polymorphism, $5 \mathrm{~mL}$ of blood was collected in EDTA tubes from each patient. The DNA extraction was carried out using QIA amp ${ }^{\circledR}$ DNA Blood Mini Kit (QIAGEN GmbH, Hilden, Germany) according to the manufacturer's instructions. ${ }^{19}$ The concentration of the extracted DNA was measured using the Nano Drop ${ }^{\circledR}$ (ND-1000) Spectrophotometer (Nano Drop Technologies Inc., Washington, USA). The ratio of absorbance of extracted DNA at $260 / 280 \mathrm{~nm}$ was 1.7-1.9.

\section{Genotyping for LEP rs7799039 Single Nucleotide Polymorphism (SNP)}

Genotyping of the LEP rs7799039 polymorphism Catalog number: 4351379 was carried out using real-time polymerase chain reaction with TaqMan ${ }^{\circledR}$ allelic discrimination assay software using (Applied Bio systems Step One TM Real Time PCR system Thermal Cycling Block, Singapore) and according to the manufacture instructions.

\section{Statistical Evaluation}

Data were analyzed using SPSS statistical software version 23 (SPSS, Inc, IL, Chicago, USA). Quantitative data were expressed as mean \pm standard deviation (SD). Qualitative data were expressed as number and percentage. Chi square test was used for comparing qualitative data between groups. Paired samples $t$ test was used for comparing parametric quantitative data between different times within the same group. Wilcoxon Signed rank test was used for comparing non-parametric quantitative data between the two times within the same group. One-way ANOVA test was used for comparing parametric quantitative data between the three groups followed by the post hoc Tukey's analysis which was used for comparing data between each two groups. Kruskal Wallis test was used for non-parametric quantitative data (expressed by median) between the three groups followed by Mann Whitney test for comparing data between each two groups. Significant level was at $\mathrm{P}$ value $\leq 0.05$.

\section{Results}

At first, 150 patients were presented to the dermatology clinic. Fifty patients were excluded (20 patients were 
receiving other treatment regimens, 2 patients had elevated liver function tests, 8 refused to sign the written consent and 20 patients had missing data in their files). Therefore, 100 patients finally were included in the study.

The included $100 \mathrm{AV}$ patients were divided into 3 groups according to LEP rs7799039 gene polymorphism. Group A (rs7799039 CC) included 59 patients, Group B (rs7799039 AC) involved 26 patients and Group C (rs7799039 AA) comprised 15 patients.

Data in Table 1 indicates that no significant differences $(\mathrm{P}<0.05)$ were shown in any of patients' clinical characteristics or demographics. Moreover, there was no significant difference in the frequency of AV types between the 3 genotypes $(\mathrm{P}=0.637)$.

Table 2 shows the impact of LEP gene rs7799039 genotypes on the biochemical parameters before and after 6 months of isotretinoin in AV patients. None of our patients had stopped the treatment due to intolerable side effects.

Fifty-four (91.5\%) patients in group A responded to isotretinoin while $8(30.8 \%)$ and $5(33.3 \%)$ patients responded to isotretinoin in group $\mathrm{B}$ and $\mathrm{C}$, respectively. Group A showed the highest response to isotretinoin followed by group B and then group $\mathrm{C}$.

TC levels had significant differences between the 3 LEP genotypes at baseline and after isotretinoin treatment $(\mathrm{P}<0.001)$. After treatment, the 3 genotypes showed significant difference $(\mathrm{P}<0.001)$ in AST levels.
Patients of Group A are associated with significant lower level of AST $(\mathrm{P}<0.001)$ and TC $(\mathrm{P}<0.001)$ after treatment (Table 2).

After treatment, patients of groups A and B showed significant lower levels $(\mathrm{P}<0.05)$ of platelets, HDL and IGF when compared with baseline values. However, the same groups showed significant higher levels $(\mathrm{P}<0.05)$ of AST, ALT, TG, TC and LDL.

Tables 3 and 4 represent the data of patients in groups 1 and 2, respectively. Table 3 shows a significant change $(\mathrm{P}<0.5)$ in all tested parameters and Table 4 shows a significant change in all parameters $(p<0.05)$ except BMI $(\mathrm{P}>0.137)$ after 6 months of treatment with oral isotretinoin.

Table 5 shows significant lower levels of BMI, platelets and $\mathrm{HDL}$ in group $\mathrm{C}$, while there is a significant increase in ALT, TC, TG and LDL after treatment.

\section{Discussion}

Isotretinoin is a retinoid that is indicated in treatment of severe recalcitrant $\mathrm{AV}^{26}$ Isotretinoin is a unique systemic therapy that mostly acts on all the major causes implicated in the pathogenesis of AV. It acts on cell-cycle progression, cellular differentiation, cell survival and apoptosis. Also, isotretinoin has anti-inflammatory properties with significant effects in reducing sebum production and lowering incidence of Propionibacterium acnes infection. ${ }^{20,21,27}$

In previous studies, LEP genotypes had shown different response to atorvastatin in diabetic patients ${ }^{28}$ and dissimilar lipid profile in obese adults. ${ }^{29}$

Table I Patients' Clinical Characteristics and Demographics $(n=100)$

\begin{tabular}{|c|c|c|c|c|c|c|c|c|}
\hline \multirow[t]{3}{*}{ Parameter } & & \multicolumn{3}{|c|}{ Leptin rs7799039 Genotypes } & \multirow{2}{*}{\multicolumn{4}{|c|}{$P$ value }} \\
\hline & & \multirow{2}{*}{$\begin{array}{l}\mathrm{CC} \\
\mathrm{N}=59\end{array}$} & \multirow{2}{*}{$\begin{array}{l}\mathrm{CA} \\
\mathrm{N}=26\end{array}$} & \multirow{2}{*}{$\begin{array}{l}\text { AA } \\
N=15\end{array}$} & & & & \\
\hline & & & & & Among 3 Groups & CC vs CA & CC vs AA & CA vs AA \\
\hline Age (years) & Mean \pm SD & $25.4 \pm 5.8$ & $25.2 \pm 7$ & $22.6 \pm 4.2$ & 0.273 & 0.993 & 0.252 & 0.377 \\
\hline Sex & $\begin{array}{l}\text { Male } \\
\text { Female }\end{array}$ & $\begin{array}{l}17(28.8 \%) \\
42(71.2 \%)\end{array}$ & $\begin{array}{l}7(26.9 \%) \\
19(73.1 \%)\end{array}$ & $\begin{array}{l}7(46.7 \%) \\
8(53.3 \%)\end{array}$ & 0.417 & 0.858 & 0.223 & 0.199 \\
\hline Smoking & $\begin{array}{l}\text { No } \\
\text { Yes }\end{array}$ & $\begin{array}{l}46(78 \%) \\
13(22 \%)\end{array}$ & $\begin{array}{l}21(80.8 \%) \\
5(19.2 \%)\end{array}$ & $\begin{array}{l}9(60 \%) \\
6(40 \%)\end{array}$ & 0.339 & 0.771 & 0.190 & 0.272 \\
\hline Type of acne & $\begin{array}{l}\text { Black head } \\
\text { Cyst } \\
\text { Papules }\end{array}$ & $\begin{array}{l}27(45.8 \%) \\
21(35.6 \%) \\
\mathrm{II}(18.6 \%)\end{array}$ & $\begin{array}{l}15(57.7 \%) \\
7(26.9 \%) \\
4(15.4 \%)\end{array}$ & $\begin{array}{l}10(66.7 \%) \\
4(26.7 \%) \\
I(6.7 \%)\end{array}$ & 0.637 & 0.638 & 0.363 & 0.894 \\
\hline Duration (years) & $\begin{array}{l}\text { Median } \\
\text { IQR }\end{array}$ & $\begin{array}{l}7 \\
(3-24)\end{array}$ & $\begin{array}{l}10 \\
(4-27)\end{array}$ & $\begin{array}{l}5 \\
(3-12)\end{array}$ & 0.534 & 0.379 & 0.606 & 0.327 \\
\hline
\end{tabular}

Note: $P<0.05$ is considered significant.

Abbreviation: IQR, interquartile range. 
Table 2 The Impact of LEP Gene rs7799039 Genotypes on the Biochemical Parameters Before and After 6 Months of Isotretinoin in Acne Vulgaris Patients $(n=100)$

\begin{tabular}{|c|c|c|c|c|c|c|c|c|}
\hline \multirow{2}{*}{\multicolumn{2}{|c|}{ Parameter }} & \multirow{2}{*}{$\begin{array}{c}\mathrm{CC} \\
\mathrm{N}=59\end{array}$} & \multirow{2}{*}{$\begin{array}{c}\mathrm{CA} \\
\mathrm{N}=26\end{array}$} & \multirow{2}{*}{$\begin{array}{c}\text { AA } \\
\mathrm{N}=15\end{array}$} & \multicolumn{4}{|c|}{$P$ value } \\
\hline & & & & & Among 3 Groups & CC vs CA & CC vs AA & CA vs $A A$ \\
\hline \multicolumn{9}{|l|}{ Before treatment } \\
\hline AST (IU/I) & Mean \pm SD & $22.3 \pm 5.9$ & $22.4 \pm 5$ & $24.1 \pm 7.9$ & 0.571 & 0.996 & 0.550 & 0.659 \\
\hline ALT (IU/I) & Mean \pm SD & $23 \pm 4.4$ & $23.5 \pm 4.6$ & $22.1 \pm 4.3$ & 0.604 & 0.879 & 0.744 & 0.575 \\
\hline TC (mg/dl) & Mean \pm SD & $172.9 \pm 23$ & $173.7 \pm 23.9$ & $214 \pm 30.2$ & $<0.00 I^{*}$ & 0.990 & $<0.00 I^{*}$ & $<0.00 I^{*}$ \\
\hline TG (mg/dl) & Mean \pm SD & $149.8 \pm 25.4$ & $147.4 \pm 24.4$ & $152.5 \pm 24.4$ & 0.817 & 0.912 & 0.928 & 0.806 \\
\hline HDL (mg/dl) & Mean \pm SD & $43.7 \pm 8.2$ & $44.6 \pm 8.3$ & $45.4 \pm 8$ & 0.754 & 0.894 & 0.766 & 0.953 \\
\hline LDL (mg/dl) & Mean \pm SD & $120.2 \pm 16.2$ & $118.7 \pm 15.2$ & $119.3 \pm 23.8$ & 0.927 & 0.925 & 0.981 & 0.993 \\
\hline Platelets $(\times 103 / \mathrm{mm} 3)$ & Median IQR & $300(220-360)$ & $220(190-300)$ & $300(230-420)$ & 0.134 & 0.198 & 0.215 & 0.060 \\
\hline IGF (nmol/l) & Mean \pm SD & $23.6 \pm 5.1$ & $24.9 \pm 4.9$ & $23.3 \pm 5.6$ & 0.505 & 0.535 & 0.979 & 0.608 \\
\hline \multicolumn{9}{|c|}{ After 6 months treatment } \\
\hline AST (IU/I) & Mean \pm SD & $25.2 \pm 5.3$ & $33.5 \pm 2.1$ & $26.6 \pm 5.1$ & $<0.001 *$ & $<0.001 *$ & 0.559 & $<0.001 *$ \\
\hline ALT (IU/I) & Mean \pm SD & $27 \pm 4.3$ & $25.7 \pm 4.5$ & $27.5 \pm 4.1$ & 0.366 & 0.438 & 0.921 & 0.433 \\
\hline TC (mg/dl) & Mean \pm SD & $189.4 \pm 29.4$ & $192.9 \pm 32.4$ & $269.7 \pm 53.3$ & $<0.001 *$ & 0.900 & $<0.001 *$ & $<0.001 *$ \\
\hline TG (mg/dl) & Mean \pm SD & $172.6 \pm 33.8$ & $166.7 \pm 29$ & $176.1 \pm 27$ & 0.616 & 0.710 & 0.925 & 0.636 \\
\hline HDL (mg/dl) & Mean \pm SD & $41.9 \pm 9.4$ & $42 \pm 10.2$ & $43.9 \pm 7.8$ & 0.766 & 0.999 & 0.754 & 0.814 \\
\hline LDL (mg/dl) & Mean \pm SD & $129.1 \pm 21.6$ & $128 \pm 20.2$ & $128.3 \pm 26.3$ & 0.973 & 0.974 & 0.991 & 0.999 \\
\hline Platelets $(\times 103 / \mathrm{mm} 3)$ & Median IQR & $207(188-255)$ & $200(179.5-282)$ & $226(187-300)$ & 0.697 & 0.947 & 0.363 & 0.597 \\
\hline IGF (nmol/l) & Mean \pm SD & $20.7 \pm 3$ & $21 \pm 2.5$ & $20.9 \pm 2.4$ & 0.893 & 0.884 & 0.984 & 0.980 \\
\hline \multirow[t]{2}{*}{ Response } & Yes n(\%) & $54(91.5 \%)$ & $8(30.8 \%)$ & $5(33.3 \%)$ & \multirow[t]{2}{*}{$<0.001 *$} & \multirow[t]{2}{*}{$<0.001 *$} & \multirow[t]{2}{*}{$<0.001 *$} & \multirow[t]{2}{*}{ I } \\
\hline & No $n(\%)$ & $5(8.5 \%)$ & $18(69.2 \%)$ & $10(66.7 \%)$ & & & & \\
\hline \multirow[t]{2}{*}{ Headache } & No n(\%) & $28(47.5 \%)$ & $12(46.2 \%)$ & $7(46.7 \%)$ & \multirow[t]{2}{*}{0.993} & \multirow[t]{2}{*}{0.912} & \multirow[t]{2}{*}{0.956} & \multirow[t]{2}{*}{0.975} \\
\hline & yes $n(\%)$ & $3 I(52.5 \%)$ & 14(53.8\%) & $8(53.3 \%)$ & & & & \\
\hline \multirow[t]{2}{*}{ Epistatxis } & No n(\%) & $24(40.7 \%)$ & $12(46.2 \%)$ & $3(20 \%)$ & \multirow[t]{2}{*}{0.234} & \multirow[t]{2}{*}{0.638} & \multirow[t]{2}{*}{0.137} & \multirow[t]{2}{*}{0.177} \\
\hline & Yes $n(\%)$ & $35(59.3 \%)$ & |4(53.8\%) & $12(80 \%)$ & & & & \\
\hline
\end{tabular}

Note: $* \mathrm{P}<0.05$ is considered significant.

Abbreviations: N, number of treated patients; AST, aspartate aminotransferase; ALT, alanine aminotransferase; TC, total cholesterol; TG, triglycerides; HDL, high density lipoprotein; LDL, low density lipoprotein; IGF, insulin-like growth factor; n (\%), number (percent).

The aim of the present study is to evaluate the impact of LEP rs7799039 gene polymorphism on response and biochemical changes of liver enzymes, lipid profile, and IGF-1 in Egyptian AV patients who received oral $0.5 \mathrm{mg} / \mathrm{kg}$ isotretinoin for 6 months.

Patients' assessment was done using IGA, which is a 5-point severity scale with a descriptive text. ${ }^{25}$ Our study has reported a decrease in the severity of acne at the end of 6 months according to the IGA. In accordance with our data, An American study had reported an improvement in IGA after 4 weeks of oral isotretinoin therapy which continued to improve through the 20 weeks of study. ${ }^{30}$ Moreover, a recent retrospective study had reported an improvement in IGA after 2 month administration of oral isotretinoin and this study had expected approximately 4- to 5-fold improvements from baseline with a full course of isotretinoin. ${ }^{31}$

This study reported significant difference in treatment response between different LEP rs 7799039 genotypes. CC genotype showed the highest response followed by 
Table 3 The Impact of LEP Gene rs7799039 Genotypes on Biochemical Parameters of Group a (rs7799039 CC) ( $\mathrm{n}=59)$

\begin{tabular}{|c|c|c|c|c|}
\hline \multicolumn{2}{|l|}{ Parameter } & \multirow{3}{*}{$\begin{array}{ll} & \text { Before } \\
\mathbf{N}=\mathbf{5 9} & \\
& 25.7 \pm 3.5 \\
\end{array}$} & \multirow{3}{*}{$\begin{array}{cc} & \text { After } \\
\mathbf{N}=59 & \\
& \\
& 25.6 \pm 3.2 \\
\end{array}$} & \multirow{3}{*}{\begin{tabular}{|c|} 
P value \\
0.265
\end{tabular}} \\
\hline & & & & \\
\hline BMI (kg/m2) & Mean \pm SD & & & \\
\hline AST (IU/I) & Mean \pm SD & $22.3 \pm 5.9$ & $25.2 \pm 5.3$ & $<0.001 *$ \\
\hline ALT (IU/I) & Mean \pm SD & $23 \pm 4.4$ & $27 \pm 4.3$ & $<0.00$ I* \\
\hline Platelets $(\times 103 / \mathrm{mm} 3)$ & Median IQR & $300(220-360)$ & $207(188-255)$ & $<0.00$ I* \\
\hline IGF (nmol/l) & Mean \pm SD & $23.6 \pm 5.1$ & $20.7 \pm 3$ & $<0.00$ I* \\
\hline TC (mg/dl) & Mean \pm SD & $172.9 \pm 23$ & $189.4 \pm 29.4$ & $<0.00$ I* \\
\hline TG (mg/dl) & Mean \pm SD & $149.8 \pm 25.4$ & $172.6 \pm 33.8$ & $<0.001 *$ \\
\hline HDL (mg/dl) & Mean \pm SD & $43.7 \pm 8.2$ & $41.9 \pm 9.4$ & $<0.001 *$ \\
\hline LDL (mg/dl) & Mean \pm SD & $120.2 \pm 16.2$ & $\mid 29.1 \pm 21.6$ & $<0.001 *$ \\
\hline
\end{tabular}

Note: $* \mathrm{P}<0.05$ is considered significant.

Abbreviations: N, number of treated patients; BMI, body mass index; AST, aspartate aminotransferase; ALT, alanine aminotransferase; TC, total cholesterol; TG, triglycerides; HDL, high density lipoprotein; LDL, low density lipoprotein; IGF, insulin-like growth factor.

CA then AA. No previous studies had discussed the predictive effect of LEP $r$ s 7799039 genotypes in efficacy of oral isotretinoin therapy in $\mathrm{AV}$ patients.

Regarding lipid profile in the present study, there was an increase of LDL, TC and TG, and a decrease of HDL in treated patients. These results coincides with a large metaanalysis review which concluded that oral isotretinoin was associated with a statistically significant change in Pennsylvanian patients' lipid profile after administration of $40 \mathrm{mg} / \mathrm{d}$ or more of isotretinoin, for at least 4 weeks. ${ }^{32}$ These changes should be followed up to avoid risk of hyperlipidemia and cardiovascular disorders associated with isotretinoin treatment. ${ }^{33,34}$

Regarding liver enzymes, this study concluded that AST and ALT levels had increased significantly after oral isotretinoin treatment. This is in agreement with an American retrospective study that reported an increase in AST and ALT levels of $\mathrm{AV}$ patients received a 3 month oral isotretinoin. ${ }^{23}$

Table 4 The Impact of LEP Gene rs7799039 Genotypes on Biochemical Parameters of Group B (rs7799039 AC) $(n=26)$

\begin{tabular}{|c|c|c|c|c|}
\hline \multicolumn{2}{|l|}{ Parameter } & \multirow{2}{*}{$\begin{array}{l}\text { Before } \\
N=26\end{array}$} & \multirow{2}{*}{$\begin{array}{l}\text { After } \\
\mathbf{N}=26\end{array}$} & \multirow[t]{2}{*}{$P$ value } \\
\hline & & & & \\
\hline BMI $(\mathrm{kg} / \mathrm{m} 2)$ & Mean \pm SD & $25.7 \pm 4.9$ & $25.4 \pm 4.5$ & 0.137 \\
\hline AST (IU/I) & Mean \pm SD & $22.4 \pm 5$ & $33.5 \pm 2.1$ & $<0.00 I^{*}$ \\
\hline ALT (IU/I) & Mean \pm SD & $23.5 \pm 4.6$ & $25.7 \pm 4.5$ & $0.004^{*}$ \\
\hline Platelets $(\times \mid 03 / \mathrm{mm} 3)$ & Median IQR & $220(190-300)$ & $200(179.5-282)$ & $0.026 *$ \\
\hline IGF (nmol/l) & Mean \pm SD & $24.9 \pm 4.9$ & $21 \pm 2.5$ & $<0.00$ I* \\
\hline TC (mg/dl) & Mean \pm SD & $173.7 \pm 23.9$ & $192.9 \pm 32.4$ & $<0.00$ I* \\
\hline TG (mg/dl) & Mean \pm SD & $147.4 \pm 24.4$ & $166.7 \pm 29$ & $<0.00$ I* \\
\hline HDL (mg/dl) & Mean \pm SD & $44.6 \pm 8.3$ & $42 \pm 10.2$ & $0.004^{*}$ \\
\hline LDL (mg/dl) & Mean \pm SD & $118.7 \pm 15.2$ & $128 \pm 20.2$ & $<0.001 *$ \\
\hline
\end{tabular}

Note: $* \mathrm{P}<0.05$ is considered significant.

Abbreviations: N, number of treated patients; BMI, body mass index; AST, aspartate aminotransferase; ALT, alanine aminotransferase; TC, total cholesterol; TG, triglycerides; HDL, high density lipoprotein; LDL, low density lipoprotein; IGF, insulin-like growth factor. 
Table 5 The Impact of LEP Gene rs7799039 Genotypes on Biochemical Parameters of Group C (rs7799039 AA) $(n=15)$

\begin{tabular}{|c|c|c|c|c|}
\hline \multirow[t]{2}{*}{ Parameter } & & Before & After & \multirow[t]{2}{*}{$P$ value } \\
\hline & & $N=15$ & $N=15$ & \\
\hline BMI (kg/m2) & Mean \pm SD & $25.4 \pm 2.3$ & $24.6 \pm 2.2$ & $0.018 *$ \\
\hline AST (IU/I) & Mean \pm SD & $24.1 \pm 7.9$ & $26.6 \pm 5.1$ & 0.242 \\
\hline ALT (IU/I) & Mean \pm SD & $22.1 \pm 4.3$ & $27.5 \pm 4.1$ & $0.002 *$ \\
\hline Platelets $(\times 103 / \mathrm{mm} 3)$ & Median IQR & $300(230-420)$ & $226(187-300)$ & $0.016 *$ \\
\hline IGF (nmol/l) & Mean \pm SD & $23.3 \pm 5.6$ & $20.9 \pm 2.4$ & 0.055 \\
\hline TC (mg/dl) & Mean \pm SD & $214 \pm 30.2$ & $269.7 \pm 53.3$ & $<0.001 *$ \\
\hline TG (mg/dl) & Mean \pm SD & $152.5 \pm 24.4$ & $|76| \pm 27$. & $<0.00 I^{*}$ \\
\hline HDL (mg/dl) & Mean \pm SD & $45.4 \pm 8$ & $43.9 \pm 7.8$ & $0.023 *$ \\
\hline LDL (mg/dl) & Mean \pm SD & $119.3 \pm 23.8$ & $128.3 \pm 26.3$ & $<0.001 *$ \\
\hline
\end{tabular}

Note: $* P<0.05$ is considered significant.

Abbreviations: N, number of treated patients; BMI, body mass index; AST, aspartate aminotransferase; ALT, alanine aminotransferase; TC, total cholesterol; TG, triglycerides; HDL, high density lipoprotein; LDL, low density lipoprotein; IGF, insulin-like growth factor.

After treatment, Group A in this study (rs7799039 CC) is associated with significant lower AST levels. On the contrary of our findings, a cross-sectional study had reported lower AST levels in LEP AA genotype in $200 \mathrm{AV}$ patients treated with oral isotretinoin for 1 month. ${ }^{35}$ This controversary may be due to difference in patients' ethnicity or difference in isotretinoin treatment duration.

In this study, group A is associated with significant lower TC levels at baseline and after treatment. Our data is accordance with findings of a recent study which reported lower TC levels in LEP rs7799039 CC genotype in Jordanian AV patients who received $40 \mathrm{mg} /$ day oral isotretinoin. $^{35}$

Platelets count decreased significantly in the three groups of patients after treatment when compared with baseline data. However, no significant differences were observed between after treatment's platelets level in the 3 LEP genotypes. The present data are in accordance with a Turkish retrospective study that reported a decrease in platelet count in $\mathrm{AV}$ patients who received oral isotretinoin for 3 months and this was explained by bone marrow suppression effects of isotretinoin. ${ }^{36}$ On the other hand, isotretinoin had shown to increase platelets count in $70 \mathrm{AV}$ patients with moderate to severe nodulo-cystic acne, who had therapeutic failure with topical remedies and tetracyclines. ${ }^{37}$ This controversy to our data may be due to different degree of severity of $\mathrm{AV}$ in the included patients.
IGF-1 has shown to affect androgen metabolism and lipogenesis. ${ }^{38}$ Additionally, IGF-1 has been shown to upregulate inflammatory cytokines in various cells including immortalized sebocytes. ${ }^{39}$ A correlation between the severity of acne and the level of serum IGF-1 has also been reported. ${ }^{11}$ In this study we noted a decrease of IGF1 in the treated groups A and B. The results agree with Karadag et al who have reported a decrease in IGF-1 after 3 month of isotretinoin therapy in AV Turkish patients. ${ }^{38,39}$ Moreover, An Egyptian study had reported similar results in female AV patients received 4 months treatment of oral isotretinoin. ${ }^{40}$ Till now, no researches had studied the impact of LEP $r s 7799039$ genotypes on IGF-1 in AV patients receiving oral isotretinoin.

In conclusion, response and lipid alterations associated with oral isotretinoin is correlated with genetic variations in LEP rs7799039. LEP rs7799039 CC genotype showed the highest response and lowest increase in AST and TC. $\mathrm{CC}$ and $\mathrm{AC}$ genotypes are associated with a significant decrease in IGF-1 in AV patients. Therefore, LEP rs7799039 CC genotype can be used as one of the selection criteria for eligible patients that would benefit from oral 6 month therapy of $0.5 \mathrm{mg} / \mathrm{kg}$ isotretinoin.

\section{Data Sharing Statement}

All data generated or analyzed during this study are included in this article. Further enquiries can be directed to the corresponding author. 


\section{Statement of Ethics}

All procedures followed were in accordance with the ethical standards of the ethical committee of National Hepatology and Tropical Medicine Institute (Approval number: 19-2020) and all procedures complied with the declaration of Helsinki. Informed consents were obtained from all patients included in the study.

\section{Author Contributions}

All authors made a significant contribution to the work reported, whether that is in the conception, study design, execution, acquisition of data, analysis and interpretation, or in all these areas; took part in drafting, revising or critically reviewing the article; gave final approval of the version to be published; have agreed on the journal to which the article has been submitted; and agree to be accountable for all aspects of the work.

\section{Disclosure}

The authors confirm that there is no conflicts of interest in this work.

\section{References}

1. Das S, Reynolds RV. Recent advances in acne pathogenesis: implications for therapy. Am J Clin Dermatol. 2014;15(6):479-488. doi:10.1007/s40257-014-0099-z

2. Yosipovitch G, Tang M, Dawn A, et al. Study of psychological stress, sebum production and acne vulgaris in adolescents. Acta Derm Venereol. 2007;87(2):135-139. doi:10.2340/00015555-0231

3. Tan J, Bahate K. A global perspective on the epidemiology of acne. Br J Dermatol. 2015;172 Suppl 1:3-12. doi:10.1111/bjd.13462

4. Bagatin E, Timpano D, Guadanhim L, et al. Acne vulgaris: prevalence and clinical forms in adolescents from São Paulo, Brazil. An Bras Dermatol. 2014;89(3):428-435. doi:10.1590/abd18064841.20142100

5. Abu El-Hamd M, Nada E, Moustafa M, Mahboob-Allah R. Prevalence of acne vulgaris and its impact of the quality of life among secondary school-aged adolescents in Sohag Province, Upper Egypt. J Cosmet Dermatol. 2017;16(3):370-373. doi:10.1111/jocd.12328

6. Vora S, Ovhal A, Jerajani H, Nair N, Chakrabortty A. Correlation of facial sebum to serum insulin-like growth factor-1 in patients with acne. $\operatorname{Br} J$ Dermatol. 2008;159(4):990-991. doi:10.1111/j.13652133.2008.08764.x

7. da Cunha MG, Fonseca FLA, Machado CDAS. Androgenic hormone profile of adult women with acne. Dermatology. 2013;226 (2):167-171. doi:10.1159/000347196

8. Humbel RE. Insulin-like growth factors I and I1. Eur J Biochem. 1990;190:445-462.

9. Deplewski D, Rosenfield RL. Growth hormone and insulin-like growth factors have different effects on sebaceous cell growth and differentiation; 1999. Available from: https://academic.oup.com/ endo/article/140/9/4089/2990731. Accessed December 8, 2021.

10. Smith TM, Cong Z, Gilliland KL, Clawson GA, Thiboutot DM. Insulin-like growth factor-1 induces lipid production in human SEB-1 sebocytes via sterol response element-binding protein-1. J Invest Dermatol. 2006;126:1226-1232. doi:10.1038/sj.jid.5700278
11. Cappel M, Mauger D, Thiboutot D. Correlation between serum levels of insulin-like growth factor 1, dehydroepiandrosterone sulfate, and dihydrotestosterone and acne lesion counts in adult women; 2005. Available from: www.archdermatol.com. Accessed December 8, 2021.

12. Smith TM, Gilliland K, Clawson GA, Thiboutot D. IGF-1 induces SREBP-1 expression and lipogenesis in SEB-1 sebocytes via activation of the phosphoinositide 3-kinase/Akt pathway. $J$ Invest Dermatol. 2008;128(5):1286-1293. doi:10.1038/sj.jid.5701155

13. Al-Suhaimi EA, Shehzad A. Leptin, resistin and visfatin: the missing link between endocrine metabolic disorders and immunity; 2013. Available from: http://www.eurjmedres.com/content/18/1/12. Accessed December 8, 2021.

14. Huh JY, Park YJ, Ham M, Kim JB. Crosstalk between adipocytes and immune cells in adipose tissue inflammation and metabolic dysregulation in obesity. Mol Cells. 2014;37(5):365-371. doi:10.14348/ molcells.2014.0074

15. Sane RS, Steinmann GG, Huang Q, et al. Mechanisms underlying benign and reversible unconjugated hyperbilirubinemia observed with faldaprevir administration in hepatitis C virus patients. J Pharmacol Exp Ther. 2014;351(2):403-412. doi:10.1124/jpet.114.218081

16. Alnory A, Gad H, Hegazy G, Shaker O. The association of vaspin rs2236242 and leptin rs7799039 polymorphism with metabolic syndrome in Egyptian women. Turkish J Med Sci. 2016;46 (5):1335-1340. doi:10.3906/sag-1502-138

17. Crescenti A, Solà R, Valls RM, Anguera A, Arola L. Polymorphisms in LEP and NPY genes modify the response to soluble fibre Plantago ovata husk intake on cardiovascular risk biomarkers. Genes Nutr. 2013;8(1):127-136. doi:10.1007/s12263-012-0303-9

18. LaPaglia N, Steiner J, Kirsteins L, Emanuele M, Emanuele N. Leptin alters the response of the growth hormone releasing factor- growth hormone-insulin-like growth factor-I axis to fasting. J Endocrinol. 1998;159(1):79-83. doi:10.1677/joe.0.1590079

19. Kraft J, Freiman A. Management of acne. C Can Med Assoc J. 2011;183(7):E430-5. doi:10.1503/cmaj.090374

20. Fogh K, Voorhees JJ, Aström A. Expression, purification, and binding properties of human cellular retinoic acid-binding protein type I and type II. Arch Biochem Biophys. 1993;300(2):751-755. doi:10.1006/abbi.1993.1104

21. Ott F, Bollag W, Geiger JM. Oral 9-cis-retinoic acid versus 13-cisretinoic acid in acne therapy. Dermatology. 1996;193(2):124-126. doi: $10.1159 / 000246226$

22. Williams RE, Doherty VR, Perkins W, Aitchison TC, Mackie RM. Staphylococcus aureus and intra-nasal mupirocin in patients receiving isotretinoin for acne. $\mathrm{Br} J$ Dermatol. 1992;126(4):362-366. doi:10.1111/j.1365-2133.1992.tb00679.x

23. Altman RS, Altman LJ, Altman JS. A proposed set of new guidelines for routine blood tests during isotretinoin therapy for acne vulgaris. Dermatology. 2002;204(3):232-235. doi:10.1159/000057887

24. Agarwal US, Besarwal RK, Bhola K. Oral isotretinoin in different dose regimens for acne vulgaris: a randomized comparative trial. Indian J Dermatol Venereol Leprol. 2011;77:688-694. doi:10.4103/ 0378-6323.86482

25. Agnew T, Furber G, Leach M, Segal L. A comprehensive critique and review of published measures of acne severity. $J$ Clin Aesthet Dermatol. 2016;9:40-52.

26. Peck GL, Olsen TG, Butkus D, et al. Isotretinoin versus placebo in the treatment of cystic acne. A randomized double-blind study. $J \mathrm{Am}$ Acad Dermatol. 1982;6(4 Pt 2 Suppl):735-745. doi:10.1016/S01909622(82)70063-5

27. Nelson AM, Gilliland KL, Cong Z, Thiboutot DM. 13-cis Retinoic acid induces apoptosis and cell cycle arrest in human SEB-1 sebocytes. J Invest Dermatol. 2006;126(10):2178-2189. doi:10.1038/sj.jid.5700289

28. Al-Azzam SI, Khabour OF, Alzoubi KH, Mukattash TL, Ghanma M, Saleh $\mathrm{H}$. The role of adiponectin gene variants in glycemic control in patients with Type 2 diabetes. Endocr Res. 2014;39(1):13-17. doi:10.3109/07435800.2013.794427 
29. Shabana HS. Leptin promoter variant G2548A is associated with serum leptin and HDL-C levels in a case control observational study in association with obesity in a Pakistani cohort. $J$ Biosci. 2016;41(2):251-255. doi:10.1007/s12038-016-9612-2

30. Zaenglein AL, Segal J, Darby C, Del RJQ. Lidose-isotretinoin administered without food improves quality of life in patients with severe recalcitrant nodular acne: an open-label, single-arm, Phase IV Study. $J$ Clin Aesthet Dermatol. 2020;13:15.

31. Secrest AM, Hopkins ZH, Frost ZE, et al. Quality of life assessed using Skindex-16 scores among patients with acne receiving isotretinoin treatment. JAMA Dermatol. 2020;156:1098-1106. doi:10.1001/ jamadermatol.2020.2330

32. Lee YH, Scharnitz TP, Muscat J, Chen A, Gupta-Elera G, Kirby JS Laboratory monitoring during isotretinoin therapy for acne: a systematic review and meta-analysis. JAMA Dermatol. 2016;152 (1):35-44. doi:10.1001/jamadermatol.2015.3091

33. Bonet ML, Ribot J, Palou A. Lipid metabolism in mammalian tissues and its control by retinoic acid. Biochim Biophys Acta. 2012;1821 (1):177-189. doi:10.1016/j.bbalip.2011.06.001

34. Laker MF, Green C, Bhuiyan AK, Shuster S. Isotretinoin and serum lipids: studies on fatty acid, apolipoprotein and intermediary metabolism. Br J Dermatol. 1987;117(2):203-206. doi:10.1111/ j.1365-2133.1987.tb04117.x
35. Khabour OF, Alzoubi KH, Firoz AS, Al-Awad RM. Association between leptin gene rs7799039 polymorphism and lipid profile changes induced by isotretinoin treatment in acne patients. Ther Clin Risk Manag. 2018;14:949-954. doi:10.2147/TCRM.S165712

36. Ataseven A, Ugur Bilgin A. Effects of isotretinoin on the platelet counts and the mean platelet volume in patients with acne vulgaris. ScientificWorldJournal. 2014;2014:156464. doi:10.1155/2014/156464

37. Serap Karadag A, Taner Ertugrul D, Takci Z. Isotretinoin modestly increases platelet count in acne patients. Derun Taner Ertugrul Zennure Tak. 2013;24(2):139-140.

38. Karadag AS, Ertugrul DT, Tutal E, Akin KO. Short-term isotretinoin treatment decreases insulin-like growth factor-1 and insulin-like growth factor binding protein-3 levels: does isotretinoin affect growth hormone physiology? Br J Dermatol. 2010;162(4):798-802. doi:10.1111/j.1365-2133.2009.09618.x

39. Karadag AS, Takci Z, Ertugrul DT, Bilgili SG, Balahoroglu R, Takir M. The effect of different doses of isotretinoin on pituitary hormones. Dermatology. 2015;230(4):354-359. doi:10.1159/ 000375370

40. Yosef A, Dawoud NM. No Correlations among insulin-like growth factor-1, homocysteine, vitamin B12, and folic acid plasma levels following isotretinoin therapy in acne vulgaris patients. JEWDS. 2018;15(1):47-53.

\section{Publish your work in this journal}

Pharmacogenomics and Personalized Medicine is an international, peer-reviewed, open access journal characterizing the influence of genotype on pharmacology leading to the development of personalized treatment programs and individualized drug selection for improved safety, efficacy and sustainability. This journal is indexed on the American Chemical Society's Chemical Abstracts Service (CAS). The manuscript management system is completely online and includes a very quick and fair peer-review system, which is all easy to use. Visit http://www.dovepress.com/testimonials.php to read real quotes from published authors. 